Revue

Revue de l'histoire des religions

de Ihistoire des religions

4 | 2006

Varia

Éric Rebillard, Religion et sépulture. L'Église, les vivants et les morts dans l'Antiquité tardive

Paris, Éditions de L'EHESS, 2003

Brigitte Beaujard

\title{
OpenEdition
}

Journals

Édition électronique

URL : http://journals.openedition.org/rhr/5215

DOI : $10.4000 /$ rhr. 5215

ISSN : 2105-2573

Éditeur

Armand Colin

Édition imprimée

Date de publication : 1 décembre 2006

Pagination : 489-492

ISBN : 978-2-2009-2106-4

ISSN : 0035-1423

Référence électronique

Brigitte Beaujard, «Éric Rebillard, Religion et sépulture. L'Église, les vivants et les morts dans l'Antiquité tardive ", Revue de l'histoire des religions [En ligne], 4 | 2006, mis en ligne le 28 janvier 2010, consulté le 22 septembre 2020. URL : http://journals.openedition.org/rhr/5215 ; DOI : https://doi.org/10.4000/rhr. 5215

Ce document a été généré automatiquement le 22 septembre 2020.

Tous droits réservés 


\section{Éric Rebillard, Religion et sépulture. L'Église, les vivants et les morts dans l'Antiquité tardive}

Paris, Éditions de L'EHESS, 2003

\section{Brigitte Beaujard}

\section{RÉFÉRENCE}

Éric Rebillard, Religion et sépulture. L'Église, les vivants et les morts dans l'Antiquité tardive, Paris, Éditions de L’EHESS, 2003, 24 cm, 243 p., («Civilisations et Sociétés », 115), $22 €$

1 En deux cents pages pleines de clarté et de passion, E. Rebillard revient sur « la genèse du cimetière chrétien dans l'Antiquité tardive » et sur le rôle joué par l'Église dans les relations entre les vivants et les morts $d u \mathrm{III}^{\mathrm{e}}$ au V $\mathrm{V}^{\mathrm{e}}$ siècle. À cette fin, il examine un immense domaine, chrétien et non-chrétien, juif et païen, et envisage successivement les habitudes funéraires des hommes de l'Antiquité tardive, la fonction funéraire des familles et des collèges, le droit funéraire, le devoir de sépulture, les rituels funèbres et la commémoration des morts par l'Église. La matière est répartie entre sept chapitres concis et rigoureux dont la trame est fournie par l'analyse de sources écrites, littéraires et juridiques essentiellement, dont de nombreux passages sont cités en français dans le texte. Dans la conclusion, l'auteur reconnaît la nécessité de confronter maintenant les résultats de son enquête avec la documentation archéologique. Les dimensions d'un livre ne le permettaient pas. C'est dommage car les vestiges matériels peuvent témoigner de pratiques ignorées des écrivains.

2 Mais d'ores et déjà, les conclusions auxquelles aboutit l'auteur sont éclairantes sur la place et les fonctions de l'Église du $\mathrm{III}^{\mathrm{e}}$ au V $\mathrm{V}^{\mathrm{e}}$ siècle. En dépit de traditions reprises par tous, à haute époque, l'Église ne disposait pas de nécropoles spécifiques. Et pourtant, selon G. de Rossi, dès la fin du II siècle, la catacombe de Calliste à Rome aurait été un cimetière chrétien ; mais cette hypothèse n'est fondée que sur un seul texte, la Refutatio 
omnium haeresium d'Hippolyte et sur une interprétation erronée d'un de ses mots, koimeterion, traduit par cimetière alors que, dans la langue chrétienne, il a certes bien un sens funéraire, mais désigne uniquement la tombe, celle du martyr en particulier. En conséquence la position adoptée par de Rossi est fragile. Quant aux areae, où sont ensevelis les martyrs de Carthage en 257, ce sont bien des enclos funéraires limités par des murs, mais leur usage n'est pas spécifiquement chrétien.

De fait, les chrétiens partagent les habitudes funéraires de leurs contemporains. Même au III ${ }^{\mathrm{e}}$ siècle, le lieu de la sépulture n'est pas déterminé par leur appartenance religieuse. Les Juifs sont ainsi inhumés dans les mêmes nécropoles que leurs concitoyens sans qu'aucune règle rabbinique n'ait statué en sens contraire. De la sorte, les catacombes juives de Rome constituent une exception inexpliquée. Comme autrefois, les familles et les collèges prennent en charge la sépulture de leurs membres, chrétiens ou non. En dépit d'affirmations contraires, l'Église ne semble pas constituer un collège et ne peut à ce titre gérer ses tombes.

4 En conséquence, les tombes chrétiennes relèvent de la même législation civile que les autres. Leur violation est considérée depuis Septime Sévère - et peut-être même Auguste - comme un délit public. Des épitaphes païennes, juives et chrétiennes menacent ceux qui la commettraient. Durant l'Antiquité tardive, c'est une attitude générale qu'adoptent aussi les évêques. Mais les interventions de ces derniers en la matière sont postérieures aux lois, surtout en Occident où la première attestée date de 533 seulement. En outre, à cette époque, les corps sont eux aussi protégés par la loi qui punit leur profanation. Ce respect du corps est sans doute responsable du passage de l'incinération à l'inhumation, souvent expliqué par la croyance chrétienne en la résurrection, alors qu'il touche indifféremment depuis le $\mathrm{III}^{\mathrm{e}}$ siècle les adeptes de toutes les religions.

5 Le devoir de sépulture n'est pas davantage propre aux chrétiens. Eux seuls cependant doivent ensevelir les corps des pauvres, des voyageurs et ceux des martyrs dont ils doivent entretenir la mémoire. Disposent-ils à cet effet de cimetières particuliers ? D'un personnel spécifique ? Peu de textes abordent ces questions avant la fin du $\mathrm{V}^{\mathrm{e}}$ siècle. Peut-être n'existe-t-il pas de solution générale. Ainsi, Ambroise, en estimant légitime la vente des vases sacrés par l'évêque pour acquérir des terrains nécessaires aux tombes, dont il ne précise pas qu'elles sont destinées aux pauvres (De off. II, 142), peut suggérer qu'à Milan tout au moins, l'Église possédait ses propres cimetières à la fin du $\mathrm{IV}^{\mathrm{e}}$ siècle. Ne pourrait-on expliquer les interventions de Damase dans les catacombes romaines de la même façon? Je ne sais. Mais si au départ, martyrs et saints divers ont été inhumés au milieu de leurs concitoyens, bien avant la fin du $\mathrm{V}^{\mathrm{e}}$ siècle, la construction de basiliques martyriales, le développement des inhumations ad sanctos attirent un nombre croissant de sépultures chrétiennes : je ne vois pas comment ces ensembles ont pu se constituer hors du contrôle épiscopal. Les questions, que pose ainsi le travail d'E. Rebillard, devraient relancer l'étude des sources archéologiques.

6 Mais il est vrai que l'Église ne semble pas préoccupée par la mort de ses membres. Sauf découverte peu probable, aucun document liturgique antérieur au VIII ${ }^{e}$ siècle ne règle les funérailles des chrétiens. Il n'existe pas de rituel chrétien de la mort; l'eucharistie funèbre est mal attestée et même interdite en Orient par un canon conciliaire (383). Les habitudes antiques survivent. L'Église n'a pas touché à ces pratiques qui relèvent de la vie privée. Toutefois, l'usage des pleureuses ou le déploiement d'un grand luxe funèbre 
sont critiqués par des Pères de l'Église qui en affirment l'inefficacité pour le sort des défunts que seules les prières et les aumônes des survivants peuvent améliorer.

7 De même, la mémoire des disparus est évoquée aux dates fixées par un usage ancestral. Aucune fête chrétienne n'a encore supplanté les Caristia ni les Parentalia qui donnent lieu comme autrefois à des banquets funéraires dont les excès sont réprouvés par les évêques. Dans les églises, on se contente d'une commémoration collective des défunts.

8 Ainsi tout le développement d'E. Rebillard met en valeur l'originalité de cette période $\mathrm{du} \mathrm{III}{ }^{\mathrm{e}}$ au $\mathrm{V}^{\mathrm{e}}$ siècle, durant laquelle la conversion au christianisme est une mutation spirituelle qui n'a pas modifié la vie privée des Anciens. Les chrétiens ne forment pas un groupe clos, ils vivent dans les cités où ils partagent le mode de vie de leurs concitoyens. Les funérailles, la sépulture - comme le mariage aussi - ne relèvent pas du religieux mais du profane qui dépend des individus et des familles et non pas de l'Église. Il fallut plusieurs siècles avant que le christianisme n'imprégnât l'ensemble de la vie. Le glissement vers des temps chrétiens dominés par l'Église se fit lentement; il est à peine amorcé au début du $\mathrm{V}^{\mathrm{e}}$ siècle. E. Rebillard le rappelle avec force et talent.

\section{AUTEURS}

BRIGITTE BEAUJARD

Université François-Rabelais (Tours) 